Widsanusan Chartarrayawadee*, Chee 0. Too, Sukunya Ross, Gareth M. Ross, Kanlaya Jumpatong, Araya Noimou and Apinya Settha

\title{
Green synthesis and stabilization of earthworm- like gold nanostructure and quasi-spherical shape using Caesalpinia sappan Linn. extract
}

https://doi.org/10.1515/gps-2017-0090

Received June 9, 2017; accepted August 8, 2017; previously published online September 23, 2017

Abstract: Green synthesis of nanoparticles (NPs) has received much attention due to biocompatibility and being facile and eco-friendly. Caesalpinia sappan Linn. (CS) is a plant found in Southeast Asia and is commonly known as sappan wood. In this research, we are the first to successfully use CS extract as reducing and stabilizing agents for the green synthesis of gold NPs (AuNPs). Colloidal solutions of AuNPs after reduction show natural red-wine and dark purple color depending on the size of AuNPs, without the interference of the orange/reddish-orange color from the CS extract. The concentration of CS was investigated for the formation and stabilization of AuNPs in colloidal solution (i.e. morphology, size and zeta potential). It was found that the optimized concentration of the reducing agent for the green synthesis of AuNPs was in the range of $0.004-0.04 \mathrm{wt} \%$ of CS. As the concentration of CS was increased, the sizes of AuNPs decreased due to the adsorption and stabilizing effect of CS. Transmission electron microscopy (TEM) analysis showed differences in size and shape of the NPs with earthworm and quasispherical characteristics. The zeta potential of AuNPs synthesized in the presence of CS was approximately in the range of $-10 \mathrm{mV}$ to $-20 \mathrm{mV}$, indicating the stability of AuNPs synthesized by CS.

Keywords: biosynthesis; Caesalpinia sappan Linn.; gold; green synthesis; nanoparticles.

\footnotetext{
*Corresponding author: Widsanusan Chartarrayawadee, Department of Chemistry, School of Science, University of Phayao, Phayao, 56000, Thailand, e-mail: widsanusan.ch@up.ac.th. http://orcid.org/0000-0002-4492-7954

Chee 0. Too: Intelligent Polymer Research Institute, University of Wollongong, Wollongong, NSW 2522, Australia

Sukunya Ross and Gareth M. Ross: Biopolymer Group, Biomaterials Excellent Centre, Department of Chemistry, Faculty of Science, Naresuan University, Phitsanulok 65000, Thailand Kanlaya Jumpatong, Araya Noimou and Apinya Settha: Department of Chemistry, School of Science, University of Phayao, Phayao, 56000 , Thailand
}

\section{Introduction}

The synthesis of metal nanoparticles (MNPs) is nowadays widely reported due to their outstanding chemical properties, special physical characteristics (i.e. small sizes, variety of shapes and large surface area) and many unique potential applications [1-3]. Among those of the MNPs in research worldwide, many current studies are focused on gold NPs (AuNPs). Synthesis, stabilization and functionalization of AuNPs and AuNP composites have been discussed widely by researchers and scientists around the world due to their facile synthesis, controllable size, and applications [4-8]. Furthermore, the surface chemistry of AuNPs is versatile, affording the possibility to be coated/ functionalized by a variety of molecules which help them to easily stabilize and expand their versatility in various applications [9-11].

Commonly, the most frequently used method for MNPs synthesis is chemical reduction by using chemical reducing agents. However, these chemical reducing agents are dangerous to humans and the environment. The use of green reducing agents from natural products such as plant extracts is an eco-friendly and environmentally friendly option to serve as a superior choice for green synthesis of MNPs. There have been many reports on the use of plant extracts as reducing agents for the synthesis of MNPs [12-26]. For example, Maham and co-workers [12] used Lotus garcinii leaf extract as a reducing agent for $\mathrm{Ag} /$ reduced graphene oxide ( $\mathrm{RGO}) / \mathrm{Fe}_{3} \mathrm{O}_{4}$ nanocomposite. Momeni and co-workers [20] synthesized $\mathrm{Cu} / \mathrm{ZnO}$ NPs using Euphorbia prolifera leaf extract. Maryami and coworkers [26] prepared $\mathrm{Ag} / \mathrm{RGO}$ nanocomposite by use of Abutilon hirtum leaf extract [26]. In the case of AuNPs, the use of various plant extracts and plant-based compounds (phytocompounds) has also been reported on green synthesis such as Citrus maxima extract, Salix alba leaves extract, baicalein and chlorogenic acid [4, 27-32].

However, to date, there have been no studies on the use of Caesalpinia sappan Linn. (CS) extract as a reducing agent and stabilizing agent for AuNPs synthesis. Hence, in this research, we aim to both reduce gold ions 
and stabilize resultant AuNPs by using the CS extract. However, the orange/reddish-orange color of the CS extract may be an obstacle because of color interference after the reduction of AuNPs. This is because the observed change in color of AuNPs colloidal solution after reduction varies from red wine to purple, which is dependent on the size of the AuNPs. Interestingly, the use of appropriate concentrations of CS extract can tackle this problem. An appropriate concentration of CS extract can act as a reducing and capping agent during the synthesis process, and also function as a stabilizing agent after the reduction process. Moreover, the obtained AuNPs colloidal solutions show a natural red wine to purple color after reduction, as indicated by most experiments.

CS has other common names such as sappan, sappanwood, brazilwood, and Indian redwood. CS is a medicinal plant used in therapy, as well as a dye for cotton fabric and silk yarn. The investigation of CS extract from heartwood with 95\% ethanol shows various chemical constituents such as xanthone, coumarin, chalcones, flavones, homoisoflavonoids and especially brazilin [33]. Brazilin (Figure 1) is a major and active ingredient which is detected in the heartwood of CS [33, 34]. This natural compound is safe and not toxic to humans. Brazilin has been reported as a medicinal compound with antioxidant, antibacterial, and anti-inflammatory properties [33, 35-37]. This natural compound can be developed for use in food, beverages, cosmetics, health, coloring agents, textile industries, pharmaceutical industries, and has also been used in medicinal applications due to its safety. Brazilin shows a yellow color in an acidic solution, an orange color in a neutral solution and appears as red in an alkaline solution. Moreover, brazilin has a greater tendency for degradation to brazilein, so brazilin is not stable and is easily converted to brazilein. Figure 1 shows brazilein, which is the oxidized form of brazilin [34]. In terms of chemical structure, brazilein has one fewer hydroxyl group because it is replaced by the carbonyl functional group from the oxidation process resulting in a red color. The oxidation of
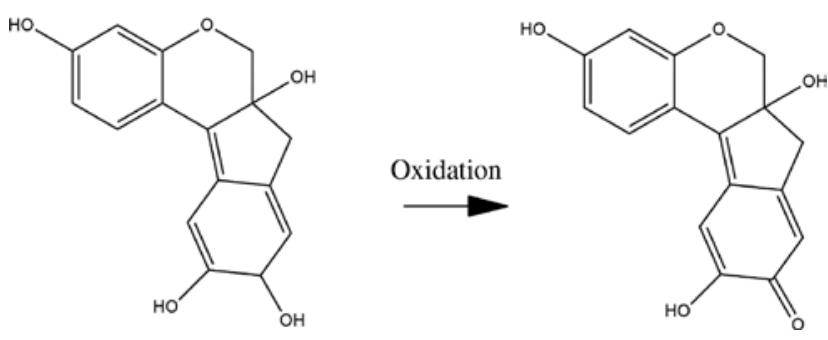

Figure 1: Structure of the major component found in Caesalpinia sappan Linn. (CS), Brazilin (left) and its oxidized form, brazilein (right). Brazilein has a red/orange red color. brazilin to brazilein occurs when it is exposed to air and light [34].

Here, we investigated the optimum concentration of CS extract for the preparation of colloidal solutions of AuNPs. The facile method we used here provides advantages in terms of its facile synthesis, low cost, ease of scale up, small size of NPs obtained, small amount of reducing and stabilizing agent (CS extract) used and environmental friendliness. This strategy will provide an additional pathway to produce colloidal AuNPs without any additional reducing or stabilizing chemical agents which have the potential to threaten the natural environment and affect living organisms.

\section{Materials and methods}

\subsection{Materials}

Tetrachloroauric (III) acid or hydrogen tetrachloroaurate (III) $\left(\mathrm{HAuCl}_{4} \cdot 4 \mathrm{H}_{2} \mathrm{O}\right)$ was obtained from Anhui Jin'Ao chemical (Anhui Jin'Ao Chemical Co., Ltd., Anhui, China). Sodium hydroxide was supplied by Labscan (RCI Labscan Limited, Samutsakorn, Thailand). All chemicals were used without further purification. Dried heartwood chips of CS were purchased from a local market in Chiangmai, Thailand.

\subsection{Preparation of CS extract}

CS heartwood chips were reduced to small flakes in a Moulinex blender and $50 \mathrm{~g}$ of heartwood flakes were boiled for $3 \mathrm{~h}$ at $80^{\circ} \mathrm{C}$ with deionized water. The ratio of heartwood flakes to deionized water was $1 \mathrm{~g}: 10 \mathrm{ml}$. After boiling for $3 \mathrm{~h}$, the solution was lyophilized to obtain red extracted powder.

\subsection{AuNP synthesis}

The green synthesis of AuNPs with CS extract as a reducing and stabilizing agent was performed as follows: hydrogen tetrachloroaurate (III) $180 \mu \mathrm{l}, 0.025 \mathrm{wt} \% \mathrm{Au}$ was added to a $25 \mathrm{ml}$ of CS solution. The mixture was adjusted until the $\mathrm{pH}$ became 7 by using $0.1 \mathrm{M} \mathrm{NaOH}$. The concentrations of CS (0.004 wt $\%, 0.01 \mathrm{wt} \%, 0.02 \mathrm{wt} \%, 0.04 \mathrm{wt} \%$, $0.12 \mathrm{wt} \%, 0.20 \mathrm{wt} \%)$ were tested for the green synthesis of AuNPs. The reaction mixture was stirred overnight $(12 \mathrm{~h})$ on a hotplate at room temperature followed by heating the colloidal solution at $90^{\circ} \mathrm{C}$ for $1 \mathrm{~h}$ until AuNPs formation was observed by the appropriate color change. The experiment was repeated at least five times in each condition to confirm the reproducibility of the experiment.

\subsection{Characterization}

UV-visible (UV-vis) absorption measurements were performed using a UV-vis spectrophotometer (Jusco, V-530, Jasco International Co., 
Ltd., Tokyo, Japan) in dual beam mode. Fourier-transform infrared (FTIR) data were collected using an FTIR spectrophotometer (Nicolet 6700, Thermo Electron Corporation, MD, USA) with Omnic software (Thermo Fisher Scientific). A laser particle sizer (Malvern Zetasizer Nano ZS, Malvern Instruments Limited, Worcestershire, UK) equipped with an He-Ne laser at $633 \mathrm{~nm}, 4 \mathrm{~mW}$ was used to determine particle size and zeta potential at $25^{\circ} \mathrm{C}$ by dynamic light scattering (DLS) in back scattering mode. An X-ray diffractometer (Rigaku Miniflex 600 $\mathrm{X}$-Ray diffractometer using $\mathrm{Cu} \mathrm{K} \alpha \mathrm{X}$-ray radiation, Rigaku Corporation, Tokyo, Japan) was used to obtain the diffraction patterns of the AuNPs on a glass slide. A transmission electron microscope (TEM, Philips Tecnai 12, FEI Company, OR, USA) was used to investigate the size and morphology of AuNPs.

\section{Results and discussion}

\subsection{Spectroscopic measurements}

UV-vis spectroscopy was used to observe the formation and stabilization of AuNPs in aqueous solution containing CS extract. Figure 2 illustrates the UV-vis spectra of AuNPs reduced by $0.004 \mathrm{wt} \%, 0.01 \mathrm{wt} \%, 0.02 \mathrm{wt} \%, 0.04 \mathrm{wt} \%$, $0.12 \mathrm{wt} \%$ and $0.20 \mathrm{wt} \%$ of CS. It can be observed that the absorbance peaks appeared around $\lambda_{\text {max }}=520-530 \mathrm{~nm}$ for the concentration range of $0.004-0.04 \mathrm{wt} \%$ of CS extract, which is characteristic of small NPs formation. When the CS extract concentration was increased (from $0.004 \mathrm{wt} \%$ to $0.04 \mathrm{wt} \%$ ), the absorbance intensity increased. However, at high concentrations of $0.12 \mathrm{wt} \%$ and $0.2 \mathrm{wt} \%$ CS extract, no absorbance peak due to AuNPS was evident, indicating that AuNPS were not formed. The reason for this could be due to the large excess of functional groups of

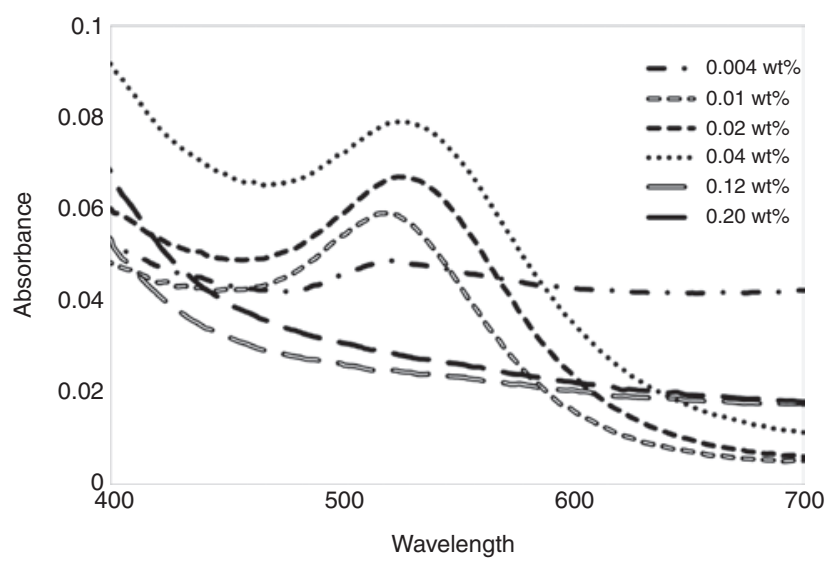

Figure 2: UV-visible spectra of different colloidal solutions of gold nanoparticles (AuNPs) reduced and stabilized with Caesalpinia sappan Linn. (CS) extract; CS concentrations vary from $0.004 \mathrm{wt} \%$ to $0.20 \mathrm{wt} \%$. the CS extract at high concentrations that overwhelmingly compete with the gold ions for the reduction process. This result indicates the formation of AuNPs due to the excitation of the surface plasmon vibrations in the AuNPs at the optimized concentration range of $0.004 \mathrm{wt} \%$ to $0.04 \mathrm{wt} \%$. The plasmon bands can appear between $520 \mathrm{~nm}$ and $570 \mathrm{~nm}$ depending on the size and shape of the AuNPs, the concentration of gold chloride precursor, solvent type and reaction temperature $[38,39]$. In addition, the formation of AuNPs can be observed by a change in color, turning red/violet after the reduction completed. Figure 3 shows the color of AuNPs colloidal solutions after the reduction completed. From (D) to (G), the colloidal solutions turned to dark purple, red, dark red and purple red for the CS concentrations of $0.004 \mathrm{wt} \%, 0.01 \mathrm{wt} \%, 0.02 \mathrm{wt} \%$ and $0.04 \mathrm{wt} \%$, respectively, indicating the formation of AuNPs in colloidal solution. Noticeably, the orange/reddish-orange color of CS extract was not observed in any AuNPs colloidal solution after reduction. Furthermore, a comparison was made with (A) CS extract $0.01 \mathrm{wt} \%$, (B) CS extract $0.01 \mathrm{wt} \% \mathrm{pH} 7$ and (C) $\mathrm{HAuCl}_{4} \cdot 4 \mathrm{H}_{2} \mathrm{O} \mathrm{pH}$. It can be observed that the CS extract was yellow and then turned to orange after the $\mathrm{pH}$ was adjusted to 7 , while $\mathrm{HAuCl}_{4} \cdot 4 \mathrm{H}_{2} \mathrm{O}$ at $\mathrm{pH} 7$ was very pale yellow. Thus, it was found that the optimized concentration for AuNPs synthesis using CS was in the range of $0.004 \mathrm{wt} \%$ to $0.04 \mathrm{wt} \%$. The stability of AuNPs colloidal solutions was subjected to testing for a whole month by doing UV-vis measurements every week. Figure 4A-D show the UV-vis spectra of AuNPs at $0.004 \mathrm{wt} \%, 0.01 \mathrm{wt} \%, 0.02 \mathrm{wt} \%$ and $0.04 \mathrm{wt} \%$ CS for 4 weeks. Figure 4A-D represent the 1st, 2nd, 3rd and 4th week measurements, respectively. Good UV-vis spectra were observed during the 4 weeks and are in good agreement with the stability. These results show the efficiency of CS extract in stabilizing AuNPs over an extended period of time. No agglomeration was observed during the first few weeks, while small aggregates were found in the 4 th week or thereafter.

FTIR spectra were obtained from the pure CS extract and dried powder isolated from AuNPs colloidal solutions (Figure 5). FTIR spectra of CS extract show a broad peak at around $3400 \mathrm{~cm}^{-1}$, attributable to the $-\mathrm{OH}$ functional group (H-bond stretching). Some other peaks at $1615 \mathrm{~cm}^{-1}$, $1507 \mathrm{~cm}^{-1}$ and $1456 \mathrm{~cm}^{-1}$ were observed which correspond to $\mathrm{C}=\mathrm{C}$ stretching vibrations in the aromatic ring. The remaining three others at $1256 \mathrm{~cm}^{-1}, 1114 \mathrm{~cm}^{-1}$ and $1035 \mathrm{~cm}^{-1}$ were also seen, which seem to correspond to C-O stretching vibration $(=\mathrm{C}-\mathrm{O}-\mathrm{C}), \mathrm{C}-\mathrm{O}-\mathrm{C}$ stretching vibration and $\mathrm{O}-\mathrm{H}$ deformation vibrations or $\mathrm{C}-\mathrm{O}$ stretching vibrations $(=\mathrm{C}-\mathrm{O}-\mathrm{H})$. These results agree with the FTIR spectra of brazilin reported by de Oliveira and co-workers [34]. 


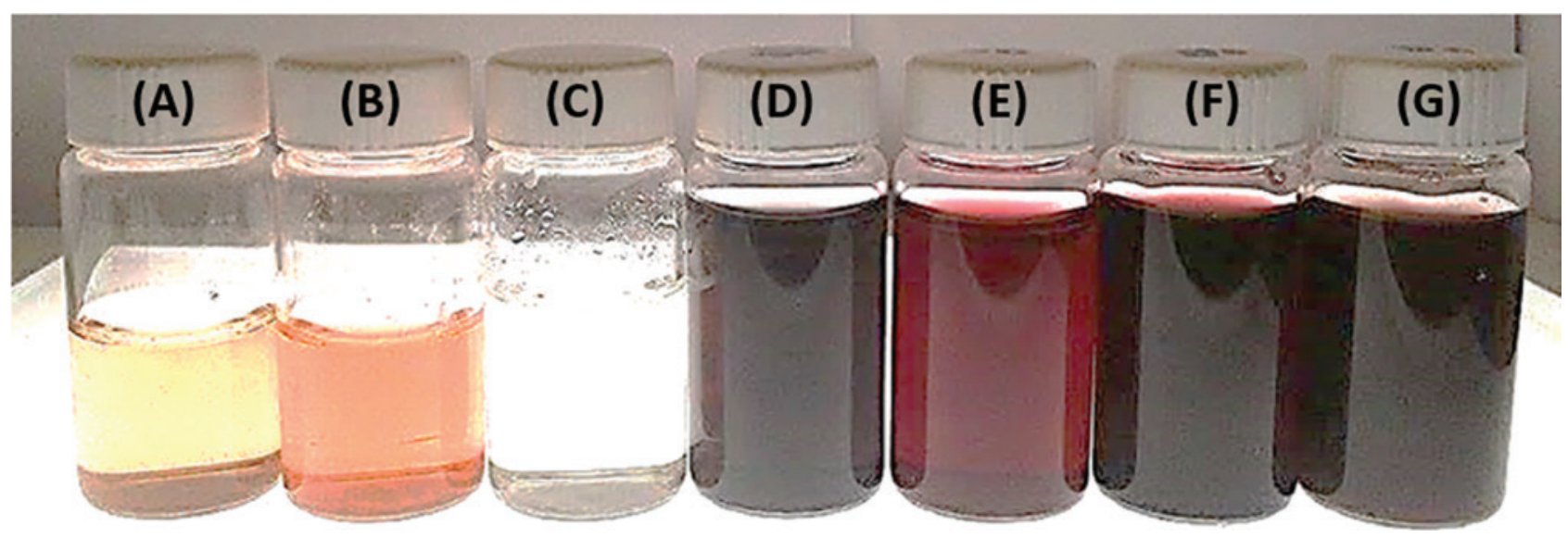

Figure 3: From left to right; (A) Caesalpinia sappan Linn. (CS) $0.01 \mathrm{wt} \%$, (B) $\mathrm{CS} 0.01 \mathrm{wt} \% \mathrm{pH} 7$, (C) $\mathrm{HAuCl}_{4} \cdot 4 \mathrm{H}_{2} \mathrm{O} \mathrm{pH}$ 7, (D) gold nanoparticles (AuNPs)/CS 0.004 wt\%, (E) AuNPs/CS 0.01 wt\%, (F) AuNPs/CS 0.02 wt\% and (G) AuNPs/CS 0.04 wt $\%$.
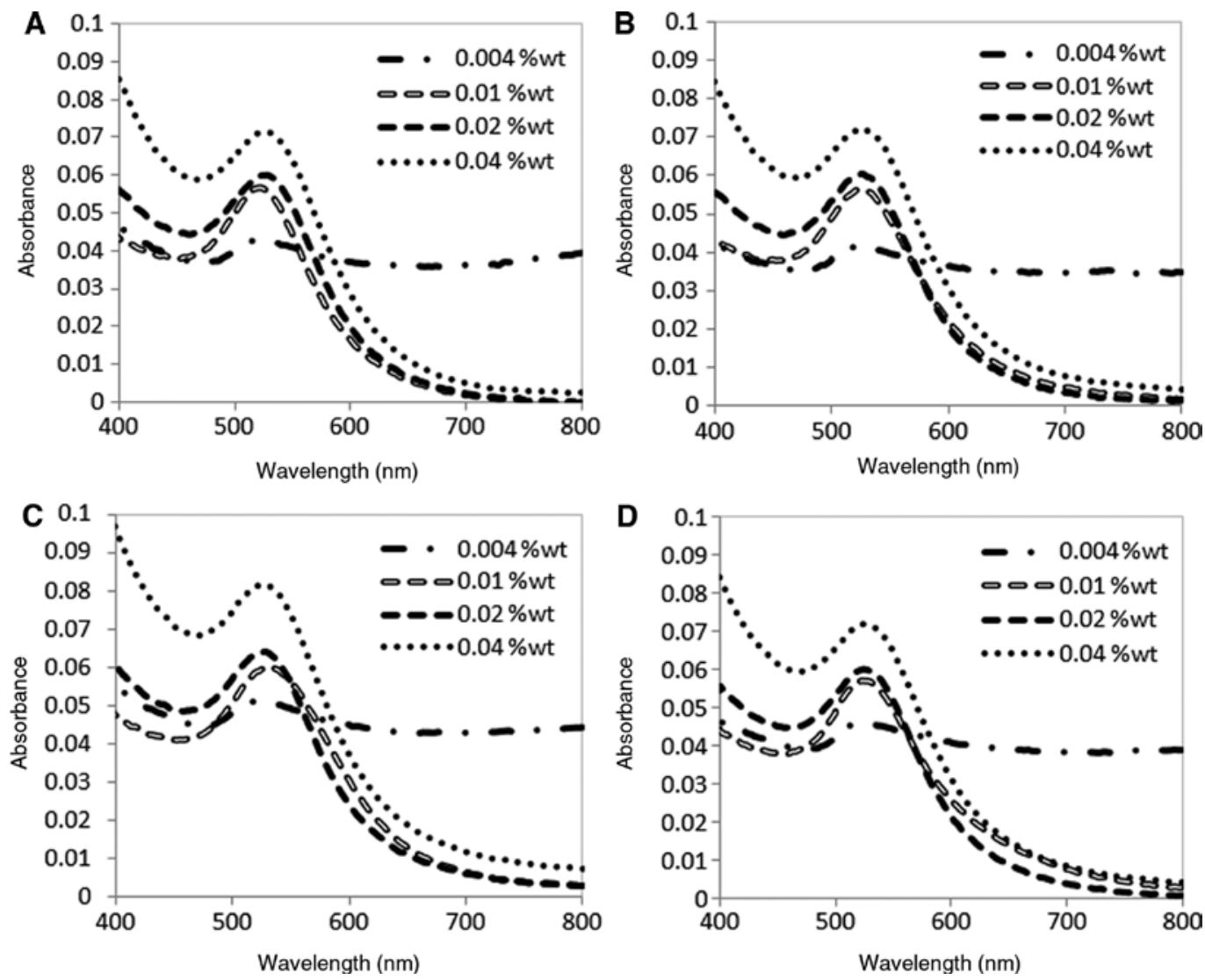

Figure 4: (A)-(D) represents UV-visible spectra of different colloidal solutions of gold nanoparticles (AuNPs) reduced and stabilized with Caesalpinia sappan Linn. (CS) extract from week 1 to week 4.

Furthermore, the high similarity between CS extract and AuNPs reduced by CS indicated that the same compounds existed in all samples. As the concentration of CS extract was increased, clear peaks in the spectra were revealed. Despite the similarity between the CS extract and AuNPs spectra, marked shifts at $3400 \mathrm{~cm}^{-1}$ and $1615 \mathrm{~cm}^{-1}$ were also observed, related to the adsorption of CS extract constituents on the AuNPs surface.

As we discussed previously, the chemical constituents found in CS heartwood are xanthone, coumarin, chalcones, flavones, homoisoflavonoids and especially brazilin. These chemical constituents are phenolic 


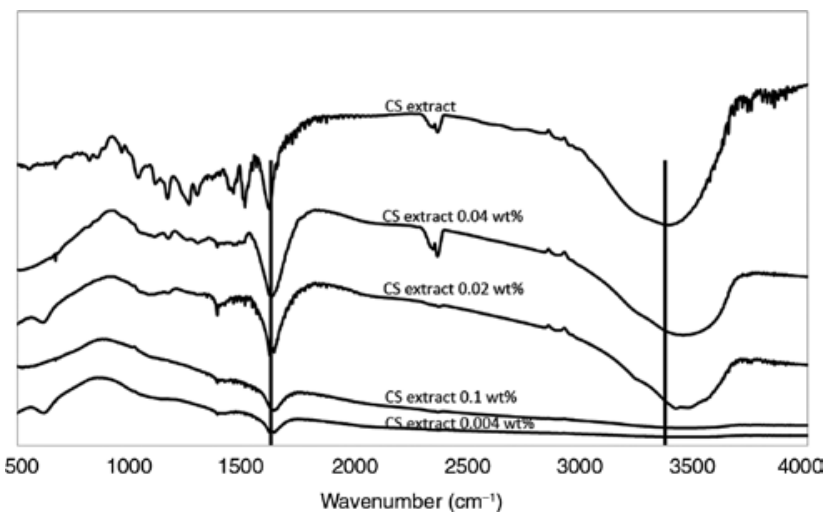

Figure 5: Typical Fourier-transform infrared spectra of Caesalpinia sappan Linn. (CS) extract and gold nanoparticles obtained using the CS extract.

compounds which are composed of mainly - $\mathrm{OH}$ functional groups that are responsible for the reduction of AuNPs by donating electrons to the gold ions. For example, brazilin, which possesses 4 hydroxyl groups in the molecular structure, can donate four electrons per molecule in the reduction process. Moreover, the hydroxyl functional groups can act as stabilizing moieties by electrostatic stabilization due to their negative charge, as confirmed by the negative zeta potential in the next section.

\subsection{Zeta potential and size distribution}

DLS was used to determine the size of AuNPs synthesized by the reduction of gold ions by the CS extract. It was found that AuNPs obtained from $0.004 \mathrm{wt} \%$ and $0.04 \mathrm{wt} \%$ CS concentrations show three different mean sizes for each condition $(20 \pm 6 \mathrm{~nm}, 223 \pm 128 \mathrm{~nm}, 4135 \pm 1044 \mathrm{~nm}$, and $41 \pm 15 \mathrm{~nm}, 213 \pm 92 \mathrm{~nm}, 4483 \pm 876 \mathrm{~nm}$, respectively), while at $0.01 \mathrm{wt} \%$ and $0.02 \mathrm{wt} \%$ of CS, there were only two different mean sizes for each condition $(16 \pm 4 \mathrm{~nm}$, $110 \pm 37 \mathrm{~nm}$, and $14 \pm 3 \mathrm{~nm}, 48 \pm 8 \mathrm{~nm}$, respectively), as shown in Table 1 . The largest mean particle sizes of $4135 \pm 1044 \mathrm{~nm}$ and $4483 \pm 876 \mathrm{~nm}$ for $0.004 \mathrm{wt} \%$ and
$0.04 \mathrm{wt} \%$, respectively, may be attributed to the agglomeration of the earthworm-like AuNPs structure and/or AuNPs clusters. Obviously, it can be seen that when the CS concentration increases, the sizes of AuNPs decrease. The smallest size of AuNPs was obtained from the use of a CS concentration of $0.02 \mathrm{wt} \%$. However, a higher concentration of CS extract may not be advantageous to produce AuNPs in this system, due to the formation of bigger particles. These results correspond to previous work published by Kim and co-workers [40] reporting the concentration effect of reducing agents (caffeic acid) on green synthesis of AuNPs. The sizes of AuNPs decreased when the concentration of caffeic acid increased, due to the adsorption and stabilizing effect of caffeic acid. However, the highest concentration of caffeic acid produced the larger size of AuNPs.

The surface charge property of AuNPs can be characterized in terms of zeta potential. The zeta potential is a crucial indicator showing the stability of colloidal dispersions/solution. The magnitude of the zeta potential is used to indicate the electrostatic interaction (repulsive or attractive) between charged particles. In the case where attractive forces exceed the repulsive forces, the value of the zeta potential is low, and may be close to zero, resulting in the particles becoming unstable and likely to aggregate or collapse. In contrast, if repulsive forces exceed attractive forces, the magnitude of the zeta potential is high, resulting in good dispersibility from stronger electrostatic repulsion. The mean zeta potential values of AuNPs stabilized by CS extract at CS concentrations of $0.004 \mathrm{wt} \%, 0.01 \mathrm{wt} \%, 0.02 \mathrm{wt} \%$ and $0.04 \mathrm{wt} \%$ (Table 1 ) are $-23.1 \pm 5.8 \mathrm{mV},-11.5 \pm 8.7 \mathrm{mV}$, $-14.9 \pm 5.9 \mathrm{mV}$ and $-17.7 \pm 8.5 \mathrm{mV}$, respectively. The mean zeta potential values are in the range of $-10 \mathrm{mV}$ to $-25 \mathrm{mV}$, indicating a medium stability for the AuNPs in colloidal solution. As we discussed previously, aggregates or sediments can be observed in AuNPs colloidal solution after a period of time. However, the aggregates or sediments can be redispersed by sonication of AuNPs colloidal solution prior to use. Furthermore, the dried

Table 1: Mean zeta potential and mean particle size corresponding to different gold nanoparticles (AuNPs) solutions reduced and stabilized with the different concentrations of Caesalpinia sappan Linn. (CS).

\begin{tabular}{|c|c|c|c|c|}
\hline $\begin{array}{l}\text { CS concentration } \\
\text { (wt\%) }\end{array}$ & $\begin{array}{r}\text { Mean zeta } \\
\text { potential }(\mathrm{mV})\end{array}$ & $\begin{array}{r}\text { Mean particle size } \\
(1 \mathrm{st} \text { peak-nm) }\end{array}$ & $\begin{array}{r}\text { Mean particle size } \\
(2 n d \text { peak-nm) }\end{array}$ & $\begin{array}{r}\text { Mean particle size } \\
\text { (3rd peak-nm) }\end{array}$ \\
\hline 0.004 & $-23.1 \pm 5.8$ & $20 \pm 6$ & $223 \pm 128$ & $4135 \pm 1044$ \\
\hline 0.01 & $-11.5 \pm 8.7$ & $16 \pm 4$ & $110 \pm 37$ & - \\
\hline 0.02 & $-14.9 \pm 5.9$ & $14 \pm 3$ & $48 \pm 8$ & - \\
\hline 0.04 & $-17.7 \pm 8.5$ & $41 \pm 15$ & $213 \pm 92$ & $4483 \pm 876$ \\
\hline
\end{tabular}


powder isolated from AuNPs colloidal solution can be redispersed in water by sonication, thus indicating the advantage of using CS extract as a reducing and stabilizing agent for AuNPs preparation.

\subsection{X-ray diffraction}

The crystalline nature of AuNPs synthesized by CS extract was further characterized by using X-ray diffraction (XRD) analysis. The XRD patterns of the synthesized AuNPs are shown in Figure $6 \mathrm{~A}-\mathrm{D}$. Four diffraction peaks were observed at $2 \theta$ values of around $38^{\circ}, 45^{\circ}, 64^{\circ}$, and $77^{\circ}$ corresponding to the (111), (200), (220), and (311) reflections of metallic crystalline gold, respectively (International Centre for Diffraction Data, ICDD No. 4-0783). XRD patterns of the synthesized AuNPs show a strong diffraction peak corresponding to the (111) facet, while the three others were less intense. These results suggest the predominance of (111) plane orientation of AuNPs. However, nearly identical diffraction peaks corresponding to the (111) and (200) facet of AuNPs at the concentration of $0.004 \mathrm{wt} \%$ were observed, showing the predominance of
(111) and (200) facet of AuNPs under this synthesis condition. However, the diffraction peaks corresponding to the (200) facet show splitting (especially observed in Figure $6 \mathrm{D})$. This suggests structural defects in the AuNPs that were sustained during synthesis [41].

\subsection{TEM morphology}

TEM images of AuNPs prepared with the concentration of $0.004 \mathrm{wt} \%$ CS extract show agglomeration of the particles with a cluster size of approximately $200 \mathrm{~nm}$. The seed of AuNPs seems to grow continuously to become an earthworm-like structure (Figure 7A and B). When the concentration of CS extract reached $0.01 \mathrm{wt} \%$, the growth of AuNPs was limited. Only quasi-spherical and short length earthworm-like structures can be observed. The small size of AuNPs starting from $5 \mathrm{~nm}$ with clusters of more than $20 \mathrm{~nm}$ can be measured by TEM (Figure 7C and D). When the CS concentration reached $0.02 \mathrm{wt} \%$, no more earthworm-like structures were observed at this stage; only AuNPs with a completely quasi-spherical shape with a size range between $5 \mathrm{~nm}$ and $10 \mathrm{~nm}$ (Figure $7 \mathrm{E}$ and F)
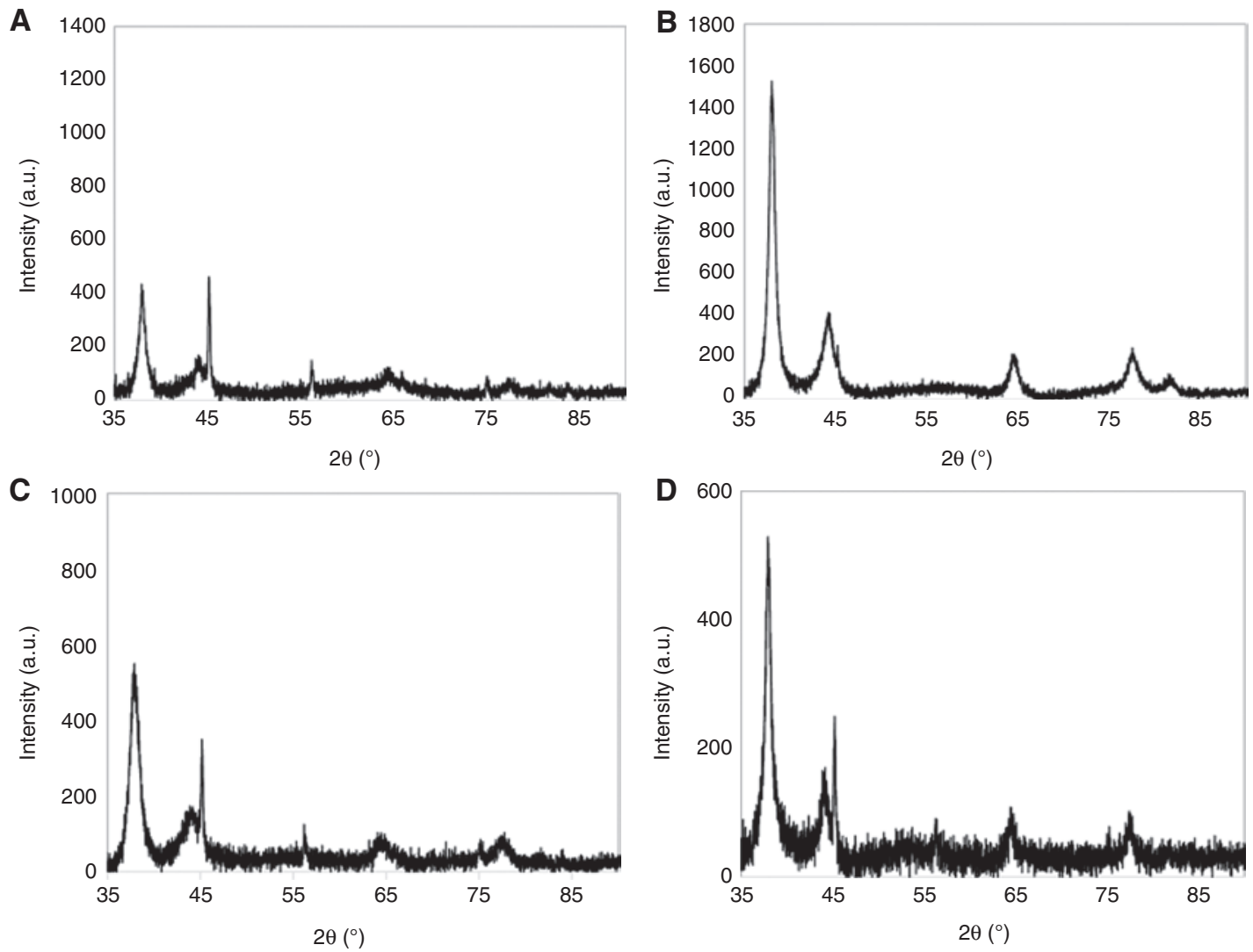

Figure 6: Powder X-ray diffraction pattern for gold nanoparticles (AuNPs) prepared with Caesalpinia sappan Linn. (CS) extract. The CS concentrations are (A) $0.004 \mathrm{wt} \% \mathrm{CS}$, (B) $0.01 \mathrm{wt} \% \mathrm{CS}$, (C) $0.02 \mathrm{wt} \%$ CS and (D) $0.04 \mathrm{wt} \% \mathrm{CS}$. 

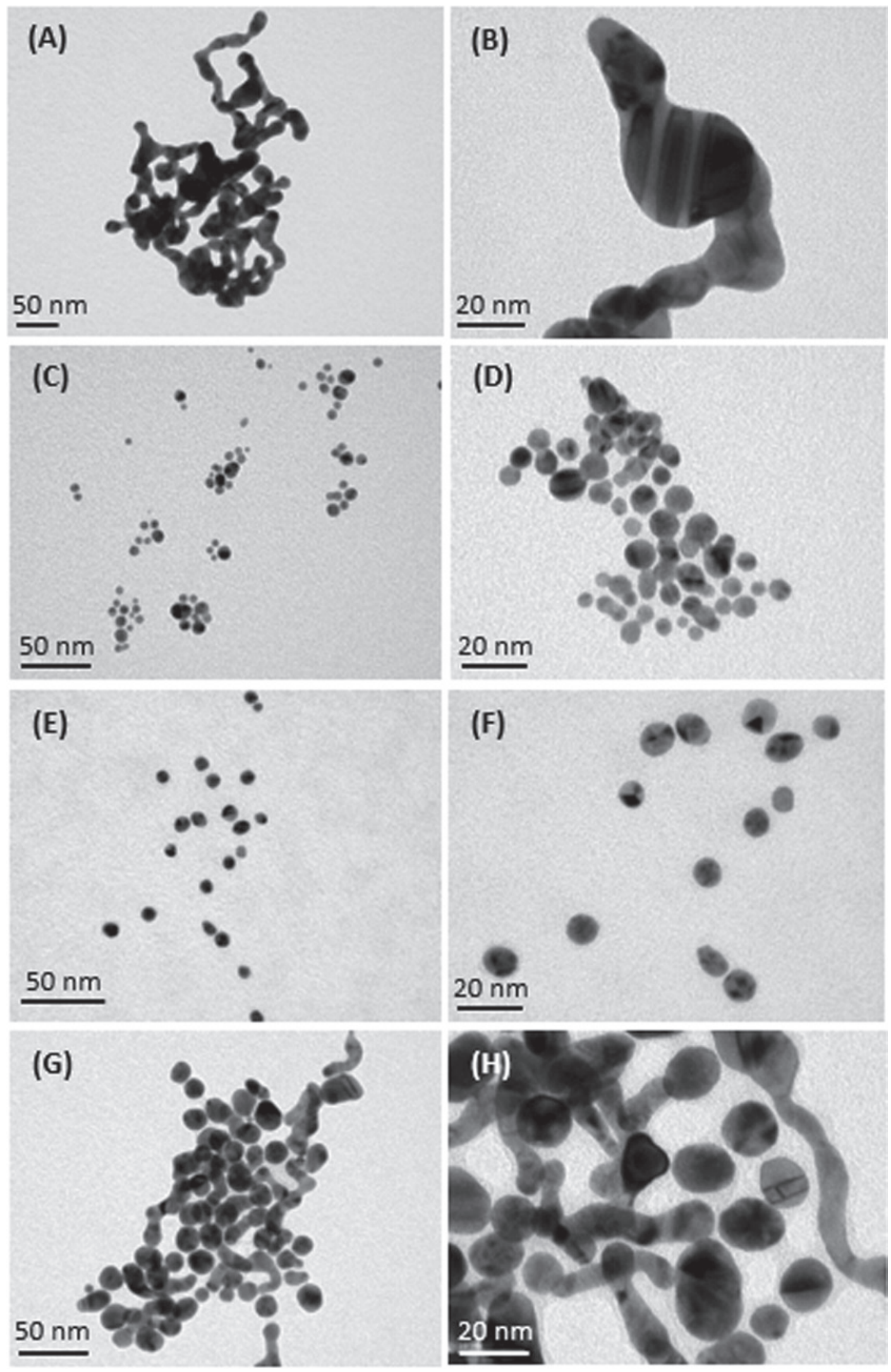

Figure 7: Transmission electron microscopy (TEM) images of gold nanoparticles (AuNPs) prepared with different Caesalpinia sappan Linn. (CS) concentrations: (A) and (B) $0.004 \mathrm{wt} \% \mathrm{CS}$, (C) and (D) $0.01 \mathrm{wt} \% \mathrm{CS}$, (E) and (F) $0.02 \mathrm{wt} \% \mathrm{CS}$, and (G) and (H) $0.04 \mathrm{wt} \% \mathrm{CS}$. Earthwormlike structures are observed at $0.004 \mathrm{wt} \%$ and $0.04 \mathrm{wt} \% \mathrm{CS}$, while the smallest AuNPs with spherical shape were obtained at $0.02 \mathrm{wt} \% \mathrm{CS}$. 
were obtained. This seems to be the best optimized condition to obtain the smallest size of AuNPs prepared with CS. Finally, on addition of CS to $0.04 \mathrm{wt} \%$ concentration, some AuNPs seem to start growing again. The combination of both quasi-spherical and earthworm-like structures was observed (Figure $7 \mathrm{G}$ and $\mathrm{H}$ ). Noticeably, the spherical shape was observed predominantly compared with the short earthworm structure. The sizes of NPs/clusters were approximately in the range of $10-200 \mathrm{~nm}$.

However, AuNPs size/cluster determined by DLS and TEM are different due to the enveloped state of particles in media which gives a hydrodynamic diameter, while TEM gives particle size in the dry state [42, 43]. The size reduction of AuNPs when CS extract was added to the system can be explained in terms of the strong interaction between the protective polyphenolic molecules and the surface of AuNPs that prevents the growth of AuNPs [44]. Furthermore, the increase in the concentration of CS extract can increase the number of nucleation sites resulting in smaller particles, while the low concentration of CS extract produces less nucleation sites, leading to more reduction and large particles formation [45]. However, the final CS concentration of $0.4 \mathrm{wt} \%$ produced both large quasi-spherical and earthworm-like structures again. This suggests that too high a CS concentration is not suitable for synthesizing small size AuNPs in this system.

\section{Conclusions}

In this research, we are the first to successfully synthesize AuNPs by green synthesis using CS extract as a reducing and stabilizing agent. The synthesis of AuNPs using CS extract has never been reported before. Synthesized AuNPs of different sizes and shapes were obtained in the range of CS concentration between $0.004 \mathrm{wt} \%$ and $0.04 \mathrm{wt} \%$. At low concentrations of CS, the shapes of the AuNPS were confined to earthworm-like structures/clusters. As the concentration of CS increases, the shapes of the AuNPS become quasi-spherical and smallest at $0.02 \mathrm{wt} \%$ CS. However, the use of the highest concentration of CS $(0.04 \mathrm{wt} \%)$ resulted in the formation of a combination of both quasi-spherical and earthworm-like structures. The obtained aqueous colloidal solutions are stable for more than a month. AuNPs colloidal solutions synthesized by this method are facile to produce, cost-effective, NPs with small size are obtained, a small amount of natural extract is used, and they are less toxic to the environment and living organisms, which is important from the point of view of green nanotechnology. Furthermore, the aqueous
AuNPs colloidal solution will be advantageous in many applications where water is required to be used as solvent, as well as affording facile synthesis, processibility, less toxicity and environmental friendliness.

Acknowledgments: The authors would like to thank the Biodiversity-Based Economy Development Office (Public Organization), National Research Council of Thailand, (grant/award number: 64/2559), Thailand's Office of the Higher Education Commission, and the University of Phayao, Thailand for the financial support.

\section{References}

[1] Abou El-Nour KMM, Eftaiha AA, Al-Warthan A, Ammar RAA. Arab. J. Chem. 2010, 3, 135-140.

[2] Ansari SM, Bhor RD, Pai KR, Sen D, Mazumder S, Ghosh K, Kolekar YD, Ramana CV. Appl. Surf. Sci. 2017, 414, 171-187.

[3] Kwon J, Mao X, Lee J. Curr. Appl. Phys. 2017, 17, 1066-1078.

[4] Yu J, Xu D, Guan HN, Wang C, Huang LK, Chi DF. Mater. Lett. 2016, 166, 110-112.

[5] Huang Y, Fang Y, Chen L, Lu A, Zhang L. Chem. Eng. J. 2017, 315, 573-582.

[6] Nazirov A, Pestov A, Privar Y, Ustinov A, Modin E, Bratskaya S. Carbohydr. Polym. 2016, 151, 649-655.

[7] Paul B, Bhuyan B, Purkayastha DD, Vadivel S, Dhar SS. Mater. Lett. 2016, 185, 143-147.

[8] Suarasan S, Focsan M, Soritau O, Maniu D, Astilean S. Colloids Surf., B. 2015, 132, 122-131.

[9] Nie Z, Petukhova A, Kumacheva E. Nat. Nanotechnol. 2010, 5, $15-25$.

[10] Lin G, Lu W. J. Colloid Interface Sci. 2017, 501, 241-247.

[11] Sperling RA, Rivera Gil P. Zhang F, Zanella M, Parak WJ. Chem. Soc. Rev. 2008, 37, 1896-1908.

[12] Maham M, Nasrollahzadeh M, Sajadi SM, Nekoei M. J. Colloid Interf. Sci. 2017, 497, 33-42.

[13] Sajjadi M, Nasrollahzadeh M, Sajadi SM. J. Colloid Interf. Sci. 2017, 497, 1-13.

[14] Maryami M, Nasrollahzadeh M, Mehdipour E, Sajadi SM. Sep. Purif. Technol. 2017, 184, 298-307.

[15] Issaabadi Z, Nasrollahzadeh M, Sajadi SM. J. Clean. Prod. 2017, 142, 3584-3591.

[16] Nasrollahzadeh M, Atarod M, Sajadi SM. J. Colloid Interf. Sci. 2017, 486, 153-162.

[17] Nasrollahzadeh M, Atarod M, Jaleh B, Gandomi M. Ceram. Int. 2016, 42, 8587-8596.

[18] Atarod M, Nasrollahzadeh M, Sajadi SM. J. Colloid Interf. Sci. 2016, 465, 249-258.

[19] Tajbakhsh M, Alinezhad H, Nasrollahzadeh M, Kamali TA. J. Alloy. Compd. 2016, 685, 258-265.

[20] Momeni SS, Nasrollahzadeh M, Rustaiyan A. J. Colloid Interf. Sci. 2016, 472, 173-179.

[21] Nasrollahzadeh M, Sajadi SM, Hatamifard A. Appl. Catal B Environ. 2016, 191, 209-227.

[22] Hatamifard A, Nasrollahzadeh M, Sajadi SM. New J. Chem. 2016, 40, 2501-2513. 
[23] Sajadi SM, Nasrollahzadeh M, Maham M. J. Colloid Interf. Sci. 2016, 469, 93-98.

[24] Nasrollahzadeh M, Atarod M, Sajadi SM. Appl. Surf. Sci. 2016, 364, 636-644.

[25] Atarod M, Nasrollahzadeh M, Sajadi SM. J. Colloid Interf. Sci. 2016, 462, 272-279.

[26] Maryami M, Nasrollahzadeh M, Mehdipour E, Sajadi SM. Int. J. Hydrogen Energy 2016, 41, 21236-21245.

[27] Rajkumari J. Busi S, Vasu AC, Reddy P. Microb. Pathog. 2017, 107, 261-269.

[28] Elia P, Zach R, Hazan S, Kolusheva S, Porat Ze, Zeiri Y. Int. J. Nanomedicine 2014, 9, 4007-4021.

[29] Hwang SJ, Jun SH, Park Y, Cha S-H, Yoon M, Cho S, Lee H-J, Park Y. Nanomedicine 2015, 11, 1677-1688.

[30] Singh AK, Srivastava ON. Nanoscale Res. Lett. 2015, 10, 353.

[31] Makarov VV, Love AJ, Sinitsyna OV, Makarova SS, Yaminsky IV, Taliansky ME, Kalinina NO. Acta Naturae. 2014, 6, 35-44.

[32] Islam NU, Jalil K, Shahid M, Rauf A, Muhammad N, Khan A, Shah MR, Khan MA. Arab. J. Chem. doi: 10.1016/j. arabjc.2015.06.025, In Press.

[33] Nirmal NP, Rajput MS, Prasad RGSV, Ahmad M. Asian Pac. J. Trop. Med. 2015, 8, 421-430.

[34] de Oliveira LFC, Edwards HGM, Velozo ES, Nesbitt M. Vib. Spectrosc. 2002, 28, 243-249.
[35] Choi B-M, Lee J-A, Gao SS, Eun SY, Kim Y-S, Ryu S-Y, Choi Y-H, Park R, Kwon DY, Kim B-R. BioFactors 2007, 30, 149-157.

[36] Nirmal NP, Panichayupakaranant P. Pharm. Biol. 2015, 53, 1339-1343.

[37] Gao X-J, Wang T-C, Zhang Z-C, Cao Y-G, Zhang N-S, Guo M-Y. Int. Immunopharmacol. 2015, 27, 130-137.

[38] Huang X, El-Sayed MA. J. Adv. Res. 2010, 1, 13-28.

[39] Dzimitrowicz A, Berent S, Motyka A, Jamroz P, Kurcbach K, Sledz W, Pohl P. Arab. J. Chem. doi: 10.1016/j.arabjc.2016.09.007, In Press.

[40] Kim H-S, Seo YS, Kim K, Han J, Park Y, Cho S. Nanoscale Res. Lett. 2016, 11, 230.

[41] Thota S, Chen S, Zhou Y, Zhang Y, Zou S, Zhao J. Nanoscale 2015, 7, 14652-14658.

[42] Nune SK, Chanda N, Shukla R, Katti K, Kulkarni RR, Thilakavathy S, Mekapothula S, Kannan R, Katti KV. J. Mater. Chem. 2009, 19, 2912-2920.

[43] Domingos RF, Baalousha MA, Ju-Nam Y, Reid MM, Tufenkji N, Lead JR, Leppard GG, Wilkinson KJ. Environ. Sci. Technol. 2009, 43, 7277-7284.

[44] Kasthuri J, Veerapandian S, Rajendiran N. Colloids Surf., $B$. 2009, 68, 55-60.

[45] Mata R, Bhaskaran A, Sadras SR. Particuology 2016, 24, 78-86. 